\title{
BMJ Open What is the general Chinese public's awareness of and attitudes towards Helicobacter pylori screening and associated health behaviours? A cross- sectional study
}

\author{
Ying-xin Wang, ${ }^{1}$ Jin-yu Zou, ${ }^{1}$ Li-feng Hu, ${ }^{1}$ Qi Liu, ${ }^{1,2}$ Ruo-lin Huang, ${ }^{1}$ Tian Tang, ${ }^{1}$ \\ Qian-qian Yue, ${ }^{1}$ Ying-Xue Sun, ${ }^{1}$ Qiao Xiao, ${ }^{1}$ Xi Zeng, ${ }^{3,4}$ Ying Zeng (D) ${ }^{1,3}$
}

To cite: Wang Y, Zou J, Hu L, et al. What is the general Chinese public's awareness of and attitudes towards Helicobacter pylori screening and associated health behaviours? A crosssectional study. BMJ Open 2022;12:e057929. doi:10.1136/ bmjopen-2021-057929

- Prepublication history for this paper is available online. To view these files, please visit the journal online (http://dx.doi org/10.1136/bmjopen-2021 057929).

$\mathrm{Y}-\mathrm{xW}$ and J-yZ contributed equally.

$\mathrm{XZ}$ and $\mathrm{YZ}$ contributed equally.

Received 06 October 2021 Accepted 12 January 2022

Check for updates

(c) Author(s) (or their employer(s)) 2022. Re-use permitted under CC BY-NC. No commercial re-use. See rights and permissions. Published by BMJ.

For numbered affiliations see end of article.

Correspondence to

Dr Ying Zeng;

zengying2003@126.com

\section{ABSTRACT}

Objective To evaluate the general population's awareness of and attitudes toward Helicobacter pylori (HP) screening and health behaviours.

Design Cross-sectional study.

Setting Hengyang, Hunan Province, China.

Participants Using stratified cluster random sampling, a pretested structured questionnaire was used to interview members of the general population aged $\geq 18$ years. Primary and secondary outcome measures Knowledge of and attitudes toward HP screening and associated health behaviours, sociodemographic factors associated with HP knowledge, and screening behaviours.

Results This study featured 1042 participants. The average knowledge score was $11\left(Q_{L}=4, Q_{U}=20\right.$, range $0-29$ ). Approximately $68.9 \%$ of the participants said they had heard of HP, but $67.5 \%$ had never had an HP test. The most common reasons for not undergoing screening were 'no symptoms' $(55.7 \%)$ and 'lack of knowledge regarding the benefits of the test' $(21.1 \%)$. Independent factors related to knowledge included age, education level, occupation, HP infection, frequency of drinking unboiled water $(p<0.05)$. Factors independently associated with screening behaviour included occupation, average monthly income, presence/absence of indigestion, stomach discomfort or pain, and/or stomach disease and knowledge score $(p<0.05)$. Overall, $941(90.3 \%)$ participants never used anti-HP toothpaste, and 442 $(40.5 \%)$ never used serving spoons or chopsticks. The risk factors for HP infection included eating out and eating in groups $(p<0.05)$.

Conclusion In China, the general population has poor knowledge of HP, but most people have a positive attitude towards HP screening. Being asymptomatic and lacking knowledge about testing were the main reasons for reluctance to be screened. These results highlight the urgent need for educational activities to raise awareness, enhance screening rates for $\mathrm{HP}$, and encourage people to adopt a healthy lifestyle.

\section{INTRODUCTION}

Helicobacter pylori (HP) infection is a major risk factor for chronic gastritis, gastric cancer

\section{Strengths and limitations of this study}

- The results may be used as a reference for other countries with high Helicobacter pylori infection rates and no screening programmes.

- As the participants' information was self-reported, recall bias may have been present.

- Only quantitative measurements were conducted.

- Other factors related to screening behaviour, such as culture and health beliefs, were not explored.

(GC) and peptic ulcer, ${ }^{1}$ and HP infection has become a global public health problem. ${ }^{2}$ The main mechanism of HP transmission is direct person-to-person. ${ }^{3}$ Globally, the average HP infection rate is $44.3 \%$; $50.8 \%$ in low-income and middle-income countries and $34.7 \%$ in developed countries. ${ }^{4}$ In 2015 , approximately 4.4 billion people worldwide had HP infections, among whom approximately 700 million were in China; the total HP infection rate in China was $55.8 \%$, higher than the mean global prevalence. ${ }^{2}$

GC is the sixth most common malignant tumour and the fourth most common cause of cancer-related deaths worldwide, and has a relatively poor prognosis. ${ }^{5}$ Most patients with GC in China are diagnosed at an advanced stage. ${ }^{6}$ The Kyoto Global consensus ${ }^{7}$ reported that HP infection is closely related to GC, and that eradication of HP is beneficial for reducing GC incidence. ${ }^{8}$ Further, a metaanalysis showed that eradication of HP can reduce GC incidence in healthy individuals and patients with gastric neoplasia, and can also reduce GC mortality. ${ }^{9}$ Therefore, improving HP-screening rates and providing early diagnosis and treatment are essential for GC prevention. 
However, although eradication of HP to prevent GC has a cost-benefit advantage, ${ }^{10}$ China lacks national policies or protocols for HP in GC screening. ${ }^{11} \mathrm{HP}$ infection is usually asymptomatic, ${ }^{12}$ and China has a large population and relatively poor medical and health resources; therefore, opportunistic screening of asymptomatic people is currently the main approach. ${ }^{13}{ }^{14}$ Such opportunistic screening is performed on a voluntary basis, based on an individual or physician's request. ${ }^{14}$ The screening rate for HP in China (21.7\%) is far from satisfactory, ${ }^{15}$ and the general population's lack of awareness of HP risk factors or symptoms and negative attitude towards screening contribute to delays in diagnosis. ${ }^{11}$

Studies ${ }^{15-20}$ have shown that the general population has poor awareness of HP. Surveys of Chinese people have reported that only $22 \%-35 \%$ have ever heard of HP. ${ }^{1620}$ Further, only $37 \%$ of medical residents in the USA feel they have sufficient knowledge regarding HP, and just 22\% would consider being tested for HP if they had no specific upper gastrointestinal symptoms. ${ }^{21}$ In a survey of migrant workers in China, in which participants were tested for HP, only $2 \%$ of those who returned positive HP results reported being previously tested for HP. ${ }^{20}$ Meanwhile, a survey of Chinese physicians and the general public found that $69.8 \%$ of the participants had at least one lifestyle habit associated with a risk of HP infection. ${ }^{15}$ Level of awareness not only affects the HP-screening rate, but also engagement in associated health behaviours. ${ }^{15} 1722$ Thus, to promote the primary prevention of GC, it is critical to improve knowledge levels regarding HP and associated health behaviours, thereby improving the HP-screening rate.

There is little information regarding the general Chinese population's knowledge and screening intentions concerning HP. Hence, this study aimed to evaluate the general population's awareness of HP, their attitudes toward HP screening, and investigate health behaviours and factors related to HP knowledge and screening behaviours.

\section{METHODS}

\section{Setting and sample}

This was a cross-sectional study was conducted between June and October 2020. The minimum sample size was calculated to be 726 . This was determined using the formula $\mathrm{N}=\left[\mu_{\mathrm{a}}{ }^{2} \times \pi \times(1-\pi)\right] / \delta^{2},{ }^{23}$ in which the prevalence rate of $21.7 \%(\pi)$ was based on the HP-screening rate for the general population, the significance level was 0.05 $(\alpha)$, and the allowable error was $0.03(\delta)$. Considering a non-response rate of $40 \%$, the final sample size was determined to be 1016 .

Using stratified cluster random sampling, 12 community health-service centres were randomly selected from the 22 such centres in Hengyang city, China. Eighty-five patients from each centre were approached for participation. We recruited 12 interviewers with a medical background and experience of investigation, and trained them in HP-related knowledge and interview skills. With the consent of the community health-service centres, each trained interviewer was accompanied by medical staff (a doctor or nurse) and approached patients for participation. The inclusion criteria were: $\geq 18$ years of age, able to communicate effectively, and willing to voluntarily participate. The exclusion criterion was having a GC diagnosis.

\section{Study instrument}

The questionnaire included items on awareness, attitudes and health behaviours related to HP. The survey items were identified through a literature review and expert consultation. ${ }^{724}$ The questionnaire comprised four parts: (1) sociodemographic characteristics, including gender, residence, marital status, education level, occupation, income, family history of GC and HP-infection status, etc. (2) 23 questions concerning knowledge of the harmfulness of HP, methods and benefits of HP treatment, HP transmission routes, and the methods of detecting and preventing HP methods. Twenty-one items were singlechoice questions; two were multiple-choice questions. One point was awarded for each correct answer, and zero points were awarded for incorrect or 'do not know' answers. The maximum total score was 29 points. The respondents' knowledge level was categorised as follows: 0-10=low knowledge, 11-19=moderate knowledge, 20-29=high knowledge. ${ }^{25}$ (3) Perceptions of HP detection, featuring nine questions: (i) 'Do you think HP infection can be prevented?' (possible responses: 'yes', 'no', 'do not know'); (ii) 'Do you think HP infections can be cured?' ('yes', 'no', 'do not know'); (iii) 'Have you ever been tested for HP? ('yes', 'no'); (iv) 'Do you think the HP test can accurately detect HP infection?' ('yes', 'no', 'do not know'); (v) 'Which HP test do you prefer?' ('13C-urea breath test', 'stool test', 'blood test', 'endoscopic biopsy', 'none', 'do not know'); (vi) 'Has your doctor discussed HP testing with you?' ('yes', 'no', 'do not remember); (vii) 'Would you like to undertake an HP test? ('yes', 'no'); (viii) 'Why do you not want to undertake an HP test?' ('lack of knowledge regarding the benefits of the test', 'a positive test would cause psychological burden', 'I have no symptoms', 'lack of time', 'economic reasons', 'other') and (ix) 'If you tested positive for HP, would you be willing to receive treatment?' ('yes', 'no'). (4) Health behaviours: including whether the participants had a salty diet; ate pickles, vegetables, fruits or sweets; used anti-HP toothpaste, brushed their teeth, drank unboiled water (well or river water); ate frequently; ate out; had group meals; used serving spoons and chopsticks; disinfected household tableware; regularly washed their hands; smoked and drank alcohol.

The questionnaire's reliability was assessed by pretesting it on 100 adults. The internal consistency was determined by estimating the Cronbach's alpha, which was found to be 0.84 . The validity of the questionnaire was evaluated using structural and content validity. The calculated Kaiser-Meyer-Olkin value was 0.886 , and the cumulative variance contribution rate was $70 \%$. The 
item-content-validity-index was $0.81-1$; the scale-contentvalidity-index was 0.914 . Based on feedback from the pretest, the questionnaire was revised and re-evaluated.

\section{Data analysis}

Data were analysed using SPSS V.23. Sociodemographic characteristics and item responses were described in terms of frequencies and percentages. Associations among sociodemographic characteristics and HP knowledge and screening behaviour, and between participants' health behaviours and HP infection, were analysed using $\chi^{2}$ tests or Fisher's exact test. Variables with $\mathrm{p} \leq 0.15$ in univariate analysis were entered into multivariate logistic regression analysis to investigate the independent factors affecting knowledge, behaviour and HP infection. The multivariate-analysis results were presented using ORs and $95 \%$ CIs, and statistical significance was set at $\mathrm{p}<0.05$.

\section{Patient and public involvement}

None of the participants were involved in the design or development of the study questions or outcome measures, or in the recruitment or implementation of the study. The results will be sent to interested participants via text message.

\section{RESULTS}

\section{Participants' sociodemographic characteristics}

From June to October 2020, 1100 individuals consented to participate in this study. After removing incomplete answers, 1042 valid questionnaires remained. The final response rate was $95 \%$. The participants' mean age was $35.40 \pm 13.3$ years (range $=18-78$ years). Over half $(62.6 \%)$ were women, $47 \%$ had high-school education or below, $61.4 \%$ lived in rural areas and $48 \%$ had low income. ${ }^{26} 27$ Sixty-seven $(6.4 \%)$ had a family history of GC, 501 (48.1\%) had symptoms of dyspepsia, stomach discomfort or pain; $124(11.9 \%)$ had HP infection and $255(24.5 \%)$ had a definite diagnosis of gastric disease. The remaining variables are listed in table 1 .

\section{Knowledge of HP}

Table 2 presents the participants' knowledge of HP, including general knowledge, awareness of HP detection and prevention methods, and indications for screening and treatment. The average knowledge score was 11 $\left(Q_{\mathrm{L}}=4, \mathrm{Q}_{\mathrm{U}}=20\right.$, range: $\left.0-29\right)$. Of the 1042 respondents, $495(47.5 \%), 370(25.9 \%)$ and $277(26.6 \%)$ had low, moderate and high knowledge of HP, respectively. Overall, $718(68.9 \%)$ had heard of HP; however, $703(67.5 \%)$ had never been tested HP. Less than $40 \%$ thought that HP infection could cause gastritis and other malignancies, or that treatment of HP prevents GC. Only 283 (27.2\%) knew about HP treatment methods. Less than $50 \%$ knew that HP could be transmitted via faecal-oral or oral transmission. Participants were also relatively unaware of the three HP-detection methods: blood test (17.2\%), stool test (29.5\%) and gastroscopic biopsy (33.9\%). The

\begin{tabular}{|c|c|}
\hline Characteristics & $\mathbf{N}(\%)$ \\
\hline \multicolumn{2}{|l|}{ Sex } \\
\hline Male & $390(37.4)$ \\
\hline Female & $652(62.6)$ \\
\hline \multicolumn{2}{|l|}{ Ages (years) } \\
\hline $18-36$ & $584(56.0)$ \\
\hline $36-60$ & $412(39.5)$ \\
\hline$\geq 60$ & $46(4.5)$ \\
\hline \multicolumn{2}{|l|}{ Education level } \\
\hline Primary school and below & $86(8.3)$ \\
\hline $\begin{array}{l}\text { Secondary school or technical secondary } \\
\text { school }\end{array}$ & $403(38.7)$ \\
\hline University or junior college & $486(46.6)$ \\
\hline Graduate student or above & $67(6.4)$ \\
\hline \multicolumn{2}{|l|}{ Occupation } \\
\hline State functionary & $60(5.8)$ \\
\hline Company staff & $185(17.8)$ \\
\hline Teacher & $73(7.0)$ \\
\hline Medical staff & $103(9.9)$ \\
\hline Worker & $79(7.6)$ \\
\hline Farmer & $117(11.2)$ \\
\hline Self-employed & $75(7.2)$ \\
\hline Student & $194(18.6)$ \\
\hline Other & $156(15.0)$ \\
\hline \multicolumn{2}{|l|}{ Marital status } \\
\hline Single & $378(36.3)$ \\
\hline Married & $638(61.3)$ \\
\hline Divorced & $13(1.2)$ \\
\hline Widowed & $13(1.2)$ \\
\hline \multicolumn{2}{|l|}{ Residence } \\
\hline Urban & $640(61.4)$ \\
\hline Rural & $402(38.6)$ \\
\hline \multicolumn{2}{|l|}{ Income $(¥)$} \\
\hline$<3000$ & $500(48.0)$ \\
\hline $3000-5000$ & $302(29.0)$ \\
\hline $5000-10000$ & $187(17.9)$ \\
\hline$\geq 10000$ & $53(5.1)$ \\
\hline \multicolumn{2}{|l|}{ Family history of gastric cancer } \\
\hline Yes & $67(6.4)$ \\
\hline No & 975 (93.6) \\
\hline \multicolumn{2}{|l|}{ Health status } \\
\hline Unhealthy & 374 (35.9) \\
\hline Suboptimal & $605(58.1)$ \\
\hline Healthy & $63(6.0)$ \\
\hline \multicolumn{2}{|l|}{ Indigestion, stomach discomfort or pain } \\
\hline Yes & $501(48.1)$ \\
\hline
\end{tabular}




\begin{tabular}{lc} 
Table 1 Continued & \\
\hline Characteristics & $541(51.9)$ \\
\hline No & \\
Helicobacter pylori infection & $124(11.9)$ \\
Yes & $215(20.6)$ \\
No & $703(67.5)$ \\
Undetected & \\
Related diseases of stomach & $255(24.5)$ \\
Yes & $600(57.6)$ \\
No & $187(17.9)$ \\
Do not know & \\
Stress & $161(15.5)$ \\
No stress & $237(22.7)$ \\
Low & $545(52.3)$ \\
Moderate & $99(9.5)$ \\
High &
\end{tabular}

most recognised indications for screening and treatment were HP infection ( $55.9 \%$ ), followed by chronic gastritis $(47.0 \%-47.4 \%)$ and peptic ulcer $(47.0 \%)$. Less well-recognised indications were long-term use of protonpump inhibitors $(24.3 \%)$, planned long-term use of nonsteroidal anti-inflammatory drugs $(22.6 \%)$, unknown causes of iron deficiency anaemia $(19.8 \%)$ and idiopathic thrombocytopenic purpura $(17.6 \%)$.

Table 3 shows the results of the multivariate analysis of factors related to HP knowledge. Univariate analysis showed that sex, age, education level, occupation, residence, average monthly income, HP-infection status, stress status, frequency of eating out, use of serving spoons and chopsticks, smoking and other factors were significantly associated with HP knowledge $(p<0.05)$. These factors plus variables with $\mathrm{p}<0.15$ in the univariate analysis were entered into the multivariate logistic regression model. The independent variables related to knowledge included sex, education level, occupation, HP infection, frequency of drinking unboiled water $(\mathrm{p}<0.05$, table 3).

Participants who were found to be less knowledgeable about HP include male sex (OR $0.63,95 \%$ CI 0.45 to 0.89 ), and those who had a lower educational level (primary school and below: OR $0.004,95 \%$ CI 0.001 to 0.03). Participants who were more knowledgeable about HP included medical professionals (OR 17.68, 95\% CI 2.15 to 145.48 ), students (OR 2.849, 95\% CI 1.318 to 6.518 ), and those who drinking unboiled water usually (never/occasionally drinking unboiled water: OR 0.427 , 95\% CI 0.200 to 0.912 ; OR 0.279 , 95\% CI 0.123 to 0.633 ). Participants with (OR 4.37, 95\% CI 2.44 to 7.82 ) and without (OR 1.95, 95\% CI 1.30 to 2.93) HP infections had better knowledge about HP than those who had never been tested for HP.
Table 2 Participants' knowledge about Helicobacter pylori $(n=1042)$

\begin{tabular}{lll}
\hline Category & Yes & $\%$ \\
\hline General knowledge & &
\end{tabular}

Have you ever heard of Helicobacter $718 \quad 68.9$ pylori?

\begin{tabular}{|c|c|c|}
\hline $\begin{array}{l}\text { Helicobacter pylori infection can } \\
\text { cause Helicobacter pylori-related } \\
\text { gastritis }\end{array}$ & 400 & 38.4 \\
\hline
\end{tabular}

Helicobacter pylori infection can $\quad 346 \quad 33.2$ cause other malignant tumours

$\begin{array}{lll}\begin{array}{l}\text { Treatment of Helicobacter pylori } \\ \text { infection can prevent gastric cancer }\end{array} & 388 & 37.2 \\ \begin{array}{l}\text { Untreated Helicobacter pylori } \\ \text { infection may lead to gastric cancer }\end{array} & 473 & 45.4\end{array}$

Helicobacter pylori infection-related $419 \quad 40.2$ gastritis can cause abdominal pain, abdominal distension, acid reflux, belching and other symptoms

Helicobacter pylori infection can $\quad 481 \quad 46.2$ be transmitted through faecal-oral transmission

Helicobacter pylori infection can be $506 \quad 48.6$
transmitted through oral-to-oral

$\begin{array}{lll}\text { The main treatments for } & 283 & 27.2\end{array}$ Helicobacter pylori infection are: two antibiotics (such as amoxicillin+clarithromycin)+proton pump inhibitors (such

as omeprazole or pantoprazole)+bismuth (such as bismuth potassium citrate).

Awareness of Helicobacter pylori detection and
prevention

Which of the following methods can detect Helicobacter pylori infection? (multiple-choice possible)

$\begin{array}{lll}\text { 13C-urea breath test } & 529 & 50.8 \\ \text { Stool tests } & 307 & 29.5 \\ \text { Blood tests } & 179 & 17.2 \\ \text { Gastroscopic biopsies } & 353 & 33.9 \\ \text { Do not know } & 368 & 35.3\end{array}$

Which of the following measures can prevent Helicobacter pylori infection?

$\begin{array}{lll}\begin{array}{l}\text { Wash hands before and after meals } \\ \text { Use chopsticks and separate meals }\end{array} & 673 & 65.1 \\ \begin{array}{l}\text { when eating } \\ \text { High temperature disinfection of }\end{array} & 669 & 64.2 \\ \text { tableware } & & \\ \begin{array}{l}\text { Avoid eating/drinking dirty food and } \\ \text { water }\end{array} & 644 & 61.8 \\ \begin{array}{l}\text { Do not know } \\ \text { Indications for screening and }\end{array} & 296 & 28.4 \\ \text { treatment } & & \end{array}$




\begin{tabular}{|c|c|c|}
\hline Category & Yes & $\%$ \\
\hline Peptic ulcers & 490 & 47.0 \\
\hline $\begin{array}{l}\text { Primary malignant lymphoma of } \\
\text { stomach }\end{array}$ & 395 & 37.9 \\
\hline Chronic gastritis with dyspepsia & 490 & 47.0 \\
\hline $\begin{array}{l}\text { Chronic gastritis with atrophy and } \\
\text { erosion of gastric mucosa }\end{array}$ & 494 & 47.4 \\
\hline $\begin{array}{l}\text { Early gastric tumours have been } \\
\text { resected under endoscope or } \\
\text { subtotal gastrectomy }\end{array}$ & 319 & 30.6 \\
\hline $\begin{array}{l}\text { Long-term use of proton- } \\
\text { pump inhibitors (omeprazole, } \\
\text { pantoprazole, etc) }\end{array}$ & 253 & 24.3 \\
\hline Family history of gastric cancer & 428 & 41.1 \\
\hline $\begin{array}{l}\text { Plan to take long-term non-steroidal } \\
\text { anti-inflammatory drugs (aspirin, } \\
\text { celecoxib, indomethacin, etc.) }\end{array}$ & 236 & 22.6 \\
\hline $\begin{array}{l}\text { Iron deficiency anaemia of unknown } \\
\text { cause }\end{array}$ & 206 & 19.8 \\
\hline $\begin{array}{l}\text { Idiopathic thrombocytopenic } \\
\text { purpura }\end{array}$ & 183 & 17.6 \\
\hline $\begin{array}{l}\text { Other Helicobacter pylori related } \\
\text { diseases }\end{array}$ & 441 & 42.3 \\
\hline $\begin{array}{l}\text { Helicobacter pylori infection was } \\
\text { confirmed by test }\end{array}$ & 582 & 55.9 \\
\hline \multicolumn{3}{|l|}{ Knowledge level (29 points) } \\
\hline Low $(0-10)$ & 495 & 47.5 \\
\hline Moderate (11-19) & 270 & 25.9 \\
\hline High (20-29) & 277 & 26.6 \\
\hline
\end{tabular}

\section{Attitudes towards HP screening}

Table 4 shows the participants' attitudes toward HP screening. Most held a positive attitude towards HP screening. Over $60 \%$ believed that HP infection could be prevented or cured, and that testing could accurately detect HP infection. The most commonly accepted test (56.9\%) was 13C-urea breath test; $16 \%$ knew nothing about HP tests. When participants were asked if their doctor had discussed HP testing with them, almost $70 \%$ said no. However, $72.3 \%$ indicated that they would like to have an HP test. Furthermore, $96.3 \%$ said they were willing to receive treatment if they tested positive for HP. Only $289(27.7 \%)$ were reluctant to undergo HP testing (because they had no symptoms $(55.7 \%)$ and lacked knowledge regarding the test's benefits $(21.1 \%)$ ).

Table 5 shows the results of the multivariate analysis of the factors associated with HP detection. Univariate analysis showed that age, occupation, marital status, residence, average monthly income, family history of GC, health status, indigestion, stomach discomfort or pain, and stomach disease, and knowledge scores were related to HP detection. These factors plus variables with $p<0.15$ in the univariate analysis were entered into the multivariate logistic regression model. The independent variables related to HP-detection behaviour included occupation, average monthly income, indigestion, stomach discomfort or pain, and stomach disease, and knowledge scores.

Participants who were less likely to undertake HP tests included workers, students, and farmers (OR 0.925, 95\% CI 0.867 to 0.988 ), and those with low monthly income (OR $0.712,95 \%$ CI 0.607 to 0.835 ) and low knowledge scores (OR $0.602,95 \%$ CI 0.507 to 0.716 ); those with symptoms of stomach discomfort (OR 1.744, 95\% CI 1.279 to 2.379) and stomach-related diseases (OR 3.326, $95 \%$ CI 2.578 to 4.292 ) were more likely to undertake the HP test.

\section{Health behaviours}

Over half of the participants $(553 ; 53.1 \%)$ reported a fruit intake of $<200 \mathrm{~g} /$ day (recommended intake for Chinese residents. ${ }^{28}$ Meanwhile, 941 (90.3\%) never used anti-HP toothpaste, and 253 (24.3\%) brushed their teeth once a day. Further, $203(19.5 \%)$ participants often eat out and $418(40.1 \%)$ often ate in groups, $442(40.5 \%)$ never used serving spoons or chopsticks and $460(44.1 \%)$ never sterilised their home tableware (table 6).

Table 7 shows the results of the multivariate analysis of factors related to HP infection. The risk factors for HP infection were eating out (OR 0.512, 95\% CI 0.322 to 0.816 ) and group eating (OR $0.564,95 \%$ CI 0.384 to $0.827)$.

\section{DISCUSSION}

Understanding the general population's awareness and attitude towards HP screening can help to develop appropriate HP prevention and screening strategies. Most of the study participants had low awareness of HP, and few had received an HP test. However, most had a positive attitude towards HP screening. The main reasons for unwillingness to undertake an HP test included absence of symptoms and insufficient knowledge regarding the test's benefits.

\section{Knowledge of HP}

This study found that the general population has poor knowledge of HP; this is similar to findings for areas with high infection rates. ${ }^{15} 17182025$ In a survey conducted in the UAE, only $24.6 \%$ had heard of HP. ${ }^{25} \mathrm{Wu}$ et al, surveying Chinese physicians and members of the general population, reported that $35 \%$ were aware of the harmfulness of HP infection. ${ }^{15}$ In surveys conducted in South Korea, $37.2 \%$ believed that HP does not cause symptoms of dyspepsia, most did not know about HP treatment methods, ${ }^{18}$ and stress, rather than HP, was considered the biggest risk factor for GC. ${ }^{17}$ In contrast, in a Singaporebased survey, where HP prevalence is low, $60 \%$ believed that gastropathy is associated with $\mathrm{HP}$ and $82.9 \%$ believed that the stomach is the site of HP infection. ${ }^{29}$ In general, the present participants had good awareness of HP transmission and prevention methods, but a poor 
Table 3 Logistic multiple regression of factors associated with Helicobacter pylori related knowledge $(n=1042)$

\begin{tabular}{|c|c|c|c|c|c|}
\hline Variable & $\boldsymbol{\beta}$ & SE & OR & $95 \% \mathrm{Cl}$ & $P$ value \\
\hline \multicolumn{6}{|l|}{ Sex } \\
\hline Male & -0.774 & 0.242 & 0.461 & 0.287 to 0.741 & 0.001 \\
\hline Female & & & & 1 (ref) & \\
\hline \multicolumn{6}{|l|}{ Education level } \\
\hline Primary school and below & -5.241 & 0.931 & 0.005 & 0.001 to 0.034 & $<0.001$ \\
\hline Secondary school or technical secondary school & -3.022 & 0.579 & 0.049 & 0.016 to 0.152 & $<0.001$ \\
\hline University or junior college & -1.715 & 0.515 & 0.180 & 0.066 to 0.494 & 0.001 \\
\hline Graduate student or above & & & & 1 (ref) & \\
\hline \multicolumn{6}{|l|}{ Occupation } \\
\hline State functionary & 0.362 & 0.442 & 1.436 & 0.603 to 3.416 & 0.414 \\
\hline Company staff & 0.364 & 0.317 & 1.439 & 0.773 to 2.680 & 0.252 \\
\hline Teacher & 0.684 & 0.407 & 1.982 & 0.893 to 4.398 & 0.093 \\
\hline Medical staff & 3.310 & 1.092 & 27.391 & 3.222 to 232.840 & 0.002 \\
\hline Worker & -0.158 & 0.401 & 0.854 & 0.389 to 1.872 & 0.693 \\
\hline Farmer & 0.570 & 0.373 & 1.769 & 0.852 to 3.670 & 0.126 \\
\hline Self-employed & 0.242 & 0.385 & 1.273 & 0.599 to 2.709 & 0.530 \\
\hline Student & 1.047 & 0.393 & 2.849 & 1.318 to 6.518 & 0.008 \\
\hline Other & & & & 1 (ref) & \\
\hline \multicolumn{6}{|l|}{ Helicobacter pylori infection } \\
\hline Yes & 1.474 & 0.297 & 4.369 & 2.440 to 7.821 & $<0.001$ \\
\hline No & 0.669 & 0.207 & 1.953 & 1.303 to 2.927 & 0.001 \\
\hline Undetected & & & & 1 (ref) & \\
\hline \multicolumn{6}{|l|}{ Drinking unboiled water } \\
\hline Never & -0.851 & 0.387 & 0.427 & 0.200 to 0.912 & 0.028 \\
\hline Occasionally & -1.278 & 0.419 & 0.279 & 0.123 to 0.633 & 0.002 \\
\hline Usual & & & & 1 (ref) & \\
\hline
\end{tabular}

Bold figures indicate the statistically significant findings $(p<0.05)$. ref, reference.

understanding of the harmfulness, therapeutic benefits, treatment, testing, and the indications for screening and treatment of HP infection. These results indicate that health education should focus on these aspects. Further, $68.9 \%$ of the present participants reported having heard of HP. This is higher than that reported in previous studies, ${ }^{1620}$ possibly because, in some areas in China with a high GC incidence, efforts have been made to eradicate HP, and publicity concerning GC and HP has increased public awareness. ${ }^{15} 30$ A Ethiopia-based meta-analysis ${ }^{31}$ suggested that Ethiopia's decreasing trend in HP infections from 1990 to 2017 was related to relative improvements in public lifestyle and behavioural changes, as well as increased awareness of the transmission, diagnosis, eradication, prevention, and control of HP infection.

Sociodemographic characteristics influence awareness of HP. Our study found that men, undereducated participants and those who had never undertaken an HP test had lower awareness. Women are more likely to assume the role of family caregivers than men, participate in nursing services, pay attention to health knowledge, and, thus, gain more knowledge about HP in this process. ${ }^{32} 33$ Meanwhile, medical staff, students and people with higher education levels may have higher awareness because they have more access to health education, ${ }^{34} \mathrm{HP}$ infection rate is closely related to socioeconomic status, ${ }^{35}$ thus, health education interventions should focus on socially disadvantaged individuals. Besides, after the HP test or treatment, people with or without HP inflection would gain more understanding of HP compared with those who have never undertake HP test. ${ }^{1536}$ Studies $^{1525}$ have mentioned that it is necessary to strengthen the general population's knowledge of HP infection. In a qualitative study on the relationship between GC and HP infection, participants voiced a strong desire for more, holistic, health education. ${ }^{37}$ Such education can be provided by hanging posters in popular places, through social media, and through medical workers. ${ }^{15} 37$

In the results of univariate analysis in this study, some health behaviours, such as the using of serving spoons and 
Table 4 Helicobacter pylori screening attitudes among participants $(n=1042)$

\begin{tabular}{lrr}
\hline Question & Number & $\%$ \\
\hline $\begin{array}{l}\text { Do you think HP infections can be } \\
\text { prevented? }\end{array}$ & \\
$\quad$ Yes & 482 & 75.0 \\
\hline No & 220 & 21.1 \\
\hline Do not know & & \\
$\begin{array}{l}\text { Do you think HP infections can be } \\
\text { cured? }\end{array}$ & 770 & 73.9 \\
$\quad$ Yes & 49 & 4.7 \\
$\quad$ No & 223 & 21.4 \\
\hline Do not know & & \\
Have you ever been tested for HP? & 284 & 27.3 \\
Yes & 758 & 72.7 \\
\hline No & & \\
\hline
\end{tabular}

Do you think the HP test can accurately detect HP infection?

\begin{tabular}{lrr}
\hline Yes & 698 & 67.0 \\
\hline No & 62 & 6.0 \\
\hline Do not know & 282 & 27.1 \\
\hline Which HP test do you prefer? & & \\
\hline 13C-urea breath test & 593 & 56.9 \\
\hline Stool tests & 93 & 8.90 \\
\hline Blood tests & 133 & 12.8 \\
\hline Endoscopic biopsy & 35 & 3.4 \\
\hline None acceptable & 21 & 2.0 \\
\hline Do not know & 167 & 16.0 \\
\hline Has your doctor discussed HP testing & & \\
with you? & & \\
\hline Yes & 215 & 20.6 \\
\hline No & 725 & 69.6 \\
\hline Do not remember & 102 & 9.8 \\
\hline Would you like to undertake an HP & & \\
test? & & 72.3 \\
\hline Yes & 753 & 27.7 \\
\hline No & 289 \\
\hline
\end{tabular}

Why do you not want to undertake an HP test $(n=289)^{*}$

\begin{tabular}{lcc}
$\begin{array}{l}\text { Lacking of knowledge regarding } \\
\text { benefits of the test }\end{array}$ & 61 & 21.1 \\
$\begin{array}{l}\text { Confirming the disease would } \\
\text { induce psychological burden }\end{array}$ & 22 & 7.6 \\
\hline No symptoms & 161 & 55.7 \\
\hline Lacking of time & 22 & 7.6 \\
\hline Economic reason & 14 & 4.8 \\
\hline Other & 9 & 3.1 \\
\hline If your tested positive for HP, would you be willing to receive \\
treatment? & 1003 & 96.3 \\
\hline Yes & 39 & 3.7 \\
\hline No & & \\
\hline
\end{tabular}

*Participants who do not want to undertake test of HP. HP, Helicobacter pylori. chopsticks, eating out and group dining, were significant with knowledge scores. Only drinking unboiled water was the influencing factor of knowledge score in the results of multivariate analysis $(\mathrm{p}<0.05)$, but it was contrary to what we expected. We speculated that the reason might be that these participants were more confident that they were in good health, ${ }^{38}$ and even though they know that drunk unboiled water was a risk factor for HP infection, they are not willing to change it. According to the Information-Motivation-Behavioral Skills model, ${ }^{39}$ the change of behaviour is affected not only by knowledge but also by motivation. This suggests that health interventions should not only improve people's knowledge of HP through health education, but also promote the formation of motivation for health behavioural change.

\section{Attitudes towards HP screening}

Most participants had a positive attitude towards HP detection, but only $27.3 \%$ had undertaken an HP test. Similarly, in Wu et al ${ }^{15} 87 \%$ of participants supported HP screening, but only $21.7 \%$ had been screened and in Shin $e a^{18}{ }^{8}$ most participants were willing to accept an HP 'detection and treatment' strategy for preventing GC, but only $36.6 \%$ had undertaken an HP test. In a Chinabased study, ${ }^{20} 81 \%$ of participants thought that they were not infected with HP, but, after testing, $41 \%$ were found to be infected. This relaxed attitude towards testing may be influenced by the manner by which HP causes GC: a multi-step process that may take decades, from chronic gastritis through atrophic gastritis, intestinal metaplasia and atypical hyperplasia to GC. ${ }^{40}$ During this process, HP infection can be asymptomatic, and may take many years for symptoms to appear. ${ }^{15}$

In this study, the primary reason for participants' reluctance to undertake an HP test was a lack of symptoms; this was not mentioned in previous studies. This is, however, similar to results from South Korea concerning gastroscopic screening for GC. ${ }^{17}$ This attitude may be related to Chinese cultural beliefs that it is unnecessary to seek medical care when there are no obvious symptoms. ${ }^{414}$ Most of the present participants said that their doctors had not discussed HP tests with them. This may be due to the poor health resources and heavy workloads of doctors, who have on average 5-hour workloads and 34.3 patients each $^{43} 44$; doctors, due to excess patient workload, may prescribe a test or treatment rather than discuss the benefits of eradicating HP. Furthermore, the general population has poor knowledge of HP; thus, even if an individual has a positive attitude toward screening, the HP test remains in a state of passive acceptance (ie, opportunistic screening, rather than active requirements).

The results of the multivariate analysis showed that occupation, monthly income, stomach discomfort symptoms status, diseases of the stomach and knowledge scores affect HP-detection behaviours. People with low monthly income were less likely to undertake an HP test than those with high monthly income. Interestingly, HP-infection risk is closely related to social status. ${ }^{3542}$ This may explain 
Table 5 Bivariate analysis of factors associated with Helicobacter pylori detection behaviour $(n=1042)$

\begin{tabular}{|c|c|c|c|c|c|}
\hline Variable & $\begin{array}{l}\text { Screened } \\
\text { N (\%) }\end{array}$ & $\begin{array}{l}\text { Unscreened } \\
\text { N (\%) }\end{array}$ & OR & $95 \% \mathrm{Cl}$ & $P$ value \\
\hline \multicolumn{6}{|l|}{ Occupation } \\
\hline Company staff & $51(27.6)$ & $134(72.4)$ & & & \\
\hline Teacher & $21(28.8)$ & $52(71.2)$ & & & \\
\hline Farmer & $26(22.2)$ & $91(77.8)$ & & & \\
\hline Self-employed & $30(40.0)$ & $45(60.0)$ & & & \\
\hline Student & $39(20.1)$ & 155 (79.9) & & & \\
\hline Other & $53(34.0)$ & $103(66.0)$ & & & \\
\hline $5000-10000$ & $66(35.3)$ & $121(64.7)$ & & & \\
\hline$\geq 10000$ & $22(41.5)$ & $31(68.5)$ & & & \\
\hline \multicolumn{6}{|c|}{ Indigestion, stomach discomfort or pain } \\
\hline Yes & $181(36.1)$ & $320(61.9)$ & 1.523 & 1.093 to 2.122 & $0.013^{*}$ \\
\hline No & $103(19.0)$ & $438(81.8)$ & & & \\
\hline \multicolumn{6}{|c|}{ Related diseases of stomach } \\
\hline Yes & $145(56.9)$ & $110(43.1)$ & 3.094 & 2.384 to 4.015 & $<0.001^{*}$ \\
\hline No & $115(19.2)$ & $485(80.8)$ & & & \\
\hline
\end{tabular}

${ }^{*}$ Statistically significant at $p<0.05$.

why, in this study, the detection rate among students, workers and farmers was lower than that for other occupations; farmers and workers also have poor access to HP-screening information. ${ }^{45}$ In contrast to individuals with no symptoms, people will seek medical care when they have symptoms of stomach discomfort or stomachrelated diseases. ${ }^{46}$ Participants with low knowledge scores were less likely to undertake HP testing because of inadequate awareness of HP risks; similarly, Wu et $a l^{15}$ found that HP awareness affects the HP-screening rate. To improve the HP-screening rate, the general population' knowledge of HP should be improved, and targeted interventions should be conducted. Furthermore, health education should focus on those who are underserved and socially disadvantaged.

\section{HP infection and health behaviours}

Some known risk factors and transmission routes of HP infection are associated with health behaviours. ${ }^{47}$ Over half of the present participants had a daily fruit intake $<200 \mathrm{~g}$, however, daily intake of $>400 \mathrm{~g}$ of vegetables or fruits is negatively correlated with HP infection. ${ }^{48}$ Consuming fruits and vegetables can also reduce the risk of HP-associated stomach cancer. ${ }^{49}$ Thus, medical professionals should encourage people to eat more fruits and vegetables. In this study, $24.3 \%$ of participants brushed their teeth only once a day, and $90.3 \%$ never used anti-HP toothpaste. The oral cavity can be a parasitic environment for HP. ${ }^{50}$ In a China-based intervention study of individuals with oral $\mathrm{HP}^{51}$ using special toothpaste two times a day removed all oral HP from $31.03 \%$ (27/87) of the participants. Therefore, medical workers should emphasised the importance of eradicating HP from the oral microenvironment and maintaining oral hygiene.

The multivariate analysis results showed that the risk factors for HP infection are eating out and group dining; this is similar to previous findings. ${ }^{51}{ }^{52}$ Studies by Monno $e t$ $a l$ showed that eating food from street vendors and eating out were associated with HP infection and may be related 


\begin{tabular}{|c|c|}
\hline Health related behaviours & $\mathbf{N}(\%)$ \\
\hline \multicolumn{2}{|l|}{ Salty diet } \\
\hline Light & $502(48.2)$ \\
\hline More salty & $513(49.2)$ \\
\hline Very salty & $27(2.6)$ \\
\hline \multicolumn{2}{|l|}{ Consumption of pickled foods } \\
\hline Never & $97(9.3)$ \\
\hline Occasionally & $848(81.4)$ \\
\hline Usual & $97(9.3)$ \\
\hline \multicolumn{2}{|c|}{ Consumption of vegetables (daily) } \\
\hline$>500 \mathrm{~g}$ & $108(10.4)$ \\
\hline $300-500 \mathrm{~g}$ & $554(53.2)$ \\
\hline$<300 \mathrm{~g}$ & $380(36.5)$ \\
\hline \multicolumn{2}{|l|}{ Consumption of fruits (daily) } \\
\hline$>350 \mathrm{~g}$ & $95(9.1)$ \\
\hline $200-350 \mathrm{~g}$ & $394(37.8)$ \\
\hline$<200 \mathrm{~g}$ & $553(53.1)$ \\
\hline \multicolumn{2}{|l|}{ Dessert intake (daily) } \\
\hline Never & $298(28.6)$ \\
\hline Occasionally & $686(65.8)$ \\
\hline Usual & $58(5.6)$ \\
\hline \multicolumn{2}{|l|}{ Using anti-HP toothpaste } \\
\hline Never & $941(90.3)$ \\
\hline Occasionally & $97(9.3)$ \\
\hline Usual & $4(0.4)$ \\
\hline \multicolumn{2}{|l|}{ Times of brushing teeth } \\
\hline$>3$ times/day & $3(0.3)$ \\
\hline 3 times/day & $51(4.9)$ \\
\hline 2 times/day & $735(70.5)$ \\
\hline 1 time/day & $253(24.3)$ \\
\hline \multicolumn{2}{|c|}{ Drinking unboiled water (well or river water) } \\
\hline Never & $772(74.1)$ \\
\hline Occasionally & $219(21.0)$ \\
\hline Usual & $51(4.9)$ \\
\hline \multicolumn{2}{|l|}{ Regular diet } \\
\hline Regular & $549(52.7)$ \\
\hline Suboptimal & $407(39.1)$ \\
\hline Irregular & $86(8.3)$ \\
\hline \multicolumn{2}{|l|}{ Eating out } \\
\hline Never & $55(5.3)$ \\
\hline Occasionally & $784(75.2)$ \\
\hline Usual & $203(19.5)$ \\
\hline \multicolumn{2}{|l|}{ Group dining } \\
\hline Never & $74(7.1)$ \\
\hline Occasionally & $550(52.8)$ \\
\hline
\end{tabular}

Continued
Table 6 Continued

\begin{tabular}{lc}
\hline Health related behaviours & N (\%) \\
\hline Usual & $418(40.1)$ \\
Use of serving spoons and chopsticks & \\
Never & $422(40.5)$ \\
\hline Occasionally & $478(45.9)$ \\
Usual & $142(13.6)$ \\
Tableware disinfection & \\
\hline 1 time/day & $198(19.0)$ \\
\hline $3-5$ times/week & $114(10.9)$ \\
\hline $1-2$ times/week & $270(25.9)$ \\
\hline Never & $460(44.1)$ \\
\hline Habit of washing hands before meals and after going to the \\
toilet & \\
\hline Every time & $736(70.6)$ \\
\hline Usual & $225(21.6)$ \\
\hline Sometimes & $81(7.8)$ \\
Smoking & \\
\hline Never & $821(78.8)$ \\
\hline Ever & $81(7.8)$ \\
\hline At present & $140(13.4)$ \\
\hline Drinking & \\
\hline Never & $674(64.7)$ \\
\hline Ever & $276(26.5)$ \\
\hline At present & $92(8.8)$ \\
\hline
\end{tabular}

to poor hygiene..$^{52} \mathrm{Xu}$ et a ${ }^{51}$ reported that poor hygiene habits, such as not using serving spoons and chopsticks and eating in groups increase the risk of HP infection. In China, the habit of not using serving spoons and chopsticks and eating in groups may play a very important role in HP infection and reinfection. A retrospective study ${ }^{53}$ conducted in Hong Kong reported that the prevalence of HP among children declined in 2005-2017, which may have been due to increased use of serving spoons and chopsticks and a decline in adult infection rates. Thus, medical workers should strengthen the publicity and provision of health knowledge, and advocate the use of serving spoons and chopsticks for group dining.

\section{Taking one step forward}

In Japan, GC screening is incorporated into the national plan. In 2000, Japan's national health insurance began supporting HP eradication in patients with peptic ulcers, and in 2013, HP-eradication treatment in patients with HP-positive chronic gastritis diagnosed by endoscopy was included in the national health insurance. ${ }^{54}{ }^{55}$ In recent years, the combination of primary prevention (through HP screening and eradication therapy) and secondary prevention (GC screening) has become a strong policy for GC prevention and control, and these medicalinsurance policies have also achieved good results. ${ }^{567} \mathrm{In}$ 
Table 7 Bivariate analysis of factors associated with Helicobacter pylori infection $(n=339)$

\begin{tabular}{lrrr} 
& \multicolumn{2}{l}{ Helicobacter pylori infection } & 95\% Cl \\
\cline { 2 - 3 } Variable & Yes N (\%) & No N (\%) & 0.322 to 0.816 \\
\hline Eating out & $2(12.5)$ & $14(87.5)$ & $0.005^{\star}$ \\
Never & $84(34.1)$ & $162(65.9)$ & \\
Occasionally & $38(49.4)$ & $39(50.6)$ & 0.384 to 0.827 \\
Usual & & $22(75.9)$ & $0.003^{*}$ \\
Group dining & $7(24.1)$ & $124(69.3)$ & \\
Never & $55(30.7)$ & $69(52.7)$ & \\
Occasionally & $62(47.3)$ & & \\
Usual & &
\end{tabular}

*Statistically significant at $\mathrm{p}<0.05$.

China, the government has concerned public awareness of cancer, implemented the Three-year Action Plan for Cancer Prevention and Control in China (2015-2017), and explored HP-eradication treatment in areas with a high incidence of GC, which is a highly cost-effective approach. ${ }^{30}$ However, there is little data regarding the effectiveness of these measures. Therefore, this study's findings can represent a basis for measuring the effectiveness of further health interventions.

This study shows that the general population lacks awareness of HP, and that there are some misunderstandings and obstacles concerning HP screening and prevention. Therefore, we make the following suggestions: First, for the prevention and control of GC, the government should consider combining primary prevention approaches with secondary prevention approaches and adding them to health insurance. ${ }^{56}$ Second, a variety of methods such as the media should publicise scientific information regarding HP. ${ }^{42}$ Third, community hospitals should strengthen health education for local people and provide community medical workers with full support for improving people's awareness of HP. Such health education should target the little-known risk factors and screening obstacles identified in this study. Additionally, health-education activities should focus on those with low incomes and poor knowledge. Fourthly, medical workers should strengthen the people's HP-prevention knowledge and promote their motivation to develop good health behaviours.

\section{Strengths and limitations}

This study investigated the general population's awareness and attitude toward HP, screening, as well as their engagement in associated health behaviours. The survey had a high response rate. However, this study had some limitations. First, as the participants' information was self-reported, recall bias may have been present. Second, some questions may have been subjective: for example, the demarcation of 'light', 'salty' and 'very salty' was not clear, this could have been evaluated by considering daily salt intake. Third, regarding the screening of behavioural barriers, only quantitative research methods were adopted; thus, the research findings require further confirmation and support. Further studies should be conducted using qualitative or mixed methods.

\section{CONCLUSIONS}

This study shows that the general population has poor knowledge of HP, and that few people have undertaken HP test. However, most people have a positive attitude toward HP screening. The main reasons for reluctance to take a test are being asymptomatic and having inadequate knowledge about the benefits of the test. Relevant health education and intervention measures should be implemented to improve, among the general population in China, awareness and screening rates of $\mathrm{HP}$ and recognition of the importance of a healthy lifestyle. Concurrently, reductions in doctors' workloads, training new doctors and giving medical workers full support to provide health education, influence people's views on diseases, and advocate regular screening should be pursued.

\section{Author affiliations}

${ }^{1}$ Hengyang Medical School, School of Nursing, University of South China, Hengyang, Hunan, China

${ }^{2}$ School of Nursing, The Hong Kong Polytechnic University, Hong Kong, Hong Kong ${ }^{3}$ Hengyang Medical School, Hunan Province Key Laboratory of Tumor Cellular \& Molecular Pathology, Cancer Research Institute, University of South China, Hengyang, Hunan, China

${ }^{4}$ Hengyang Medical School, Hunan Province Cooperative Innovation Center for Molecular Target New Drug Study, University of South China, Hengyang, Hunan, China

Acknowledgements The authors thank all the participants in this study. We are grateful to Professor Shui-dong Feng on statistical consultation. We also gratefully acknowledge Professor De-liang Cao and Professor Qian Tao (The Chinese University of Hong Kong) for their advice with manuscript writing.

Contributors Conceptualisation: YZ, XZ, Y-xW and J-yZ. Data curation: YZ, XZ, Y-xW, J-yZ, L-fH. Investigation: Y-xW, J-yZ, L-fH, QL, R-IH, TT, Q-qY, Y-xS, QX. Methodology: YZ, XZ. Software: QL. Writing original draft: YZ, Y-xW, J-yZ. Writing review and editing: YZ, XZ. Guarantor: YZ, Y-XW.

Funding This study was funded by the National Natural Science Foundation of China (NSFC), Grant/Award number: 81641112; Hunan Provincial Natural Science Foundation of China, Grant/Award number: 2019JJ50521, 2019JJ40254; Hunan 
Excellent Young Teachers Fund, Grant/Award number: 2018191RQG010; Excellent Youth Project of Hunan Provincial Department of Education, Grant/Award number: 19B495; University of South China Innovation Foundation for Postgraduate, Grant/ Award: 213YXC013; The University of South China Innovation \& Entrepreneurship Foundation for Undergraduate, Grant/Award: 210XCX193; 210XCX195 . This work was also supported by the construction programme of the key discipline in Hunan Province, Center for Gastric Cancer Research of Hunan Province and Key Laboratory of Tumour Cellular \& Molecular Pathology (Hengyang Medical School, University of South China).

Competing interests None declared.

Patient and public involvement Patients and/or the public were not involved in the design, or conduct, or reporting, or dissemination plans of this research.

Patient consent for publication Not applicable.

Ethics approval This study involves human participants and was approved by the Ethic Committee of the University of South China (number 4304082008946). Participants gave informed consent to participate in the study before taking part.

Provenance and peer review Not commissioned; externally peer reviewed.

Data availability statement Data are available upon reasonable request. Date are available upon reasonable request. Date are available by contacting Ying Zeng by email: zengying2003@126.com.

Open access This is an open access article distributed in accordance with the Creative Commons Attribution Non Commercial (CC BY-NC 4.0) license, which permits others to distribute, remix, adapt, build upon this work non-commercially, and license their derivative works on different terms, provided the original work is properly cited, appropriate credit is given, any changes made indicated, and the use is non-commercial. See: http://creativecommons.org/licenses/by-nc/4.0/.

ORCID iD

Ying Zeng http://orcid.org/0000-0003-2795-4616

\section{REFERENCES}

1 Parikh NS, Ahlawat R. Helicobacter Pylori. In: StatPearls. Treasure Island (FL): StatPearls Publishing LLC, 2021.

2 Hooi JKY, Lai WY, Ng WK, et al. Global prevalence of Helicobacter pylori infection: systematic review and meta-analysis. Gastroenterology 2017:153:420-9.

3 Mezmale L, Coelho LG, Bordin D, et al. Review: epidemiology of Helicobacter pylori. Helicobacter 2020;25 Suppl 1:e12734.

4 Zamani M, Ebrahimtabar F, Zamani V, et al. Systematic review with meta-analysis: the worldwide prevalence of Helicobacter pylori infection. Aliment Pharmacol Ther 2018;47:868-76.

5 Sung H, Ferlay J, Siegel RL, et al. Global cancer statistics 2020: GLOBOCAN estimates of incidence and mortality worldwide for 36 cancers in 185 countries. CA Cancer J Clin 2021;71:209-49.

6 Wang F-H, Shen L, Li J, et al. The Chinese Society of clinical oncology (CSCO): clinical guidelines for the diagnosis and treatment of gastric cancer. Cancer Commun 2019;39:10.

7 Sugano K, Tack J, Kuipers EJ, et al. Kyoto global consensus report on Helicobacter pylori gastritis. Gut 2015;64:1353-67.

8 Ford AC, Yuan Y, Forman D, et al. Helicobacter pylori eradication for the prevention of gastric neoplasia. Cochrane Database Syst Rev 2020;7:Cd005583.

9 Ford AC, Yuan Y, Moayyedi P. Helicobacter pylori eradication therapy to prevent gastric cancer: systematic review and meta-analysis. Gut 2020;69:2113-21.

10 Kowada A, Asaka M. Economic and health impacts of introducing Helicobacter pylori eradication strategy into national gastric cancer policy in Japan: a cost-effectiveness analysis. Helicobacter 2021;26:e12837.

11 Zong L, Abe M, Seto Y, et al. The challenge of screening for early gastric cancer in China. Lancet 2016;388:2606.

12 Lapidot Y, Reshef L, Cohen D, et al. Helicobacter pylori and the intestinal microbiome among healthy school-age children Helicobacter 2021;26:e12854.

13 Chai K-C, Zhang Y-B, Chang K-C. Regional disparity of medical resources and its effect on mortality rates in China. Front Public Health 2020;8:8

14 Tao W, Wang H-X, Guo Y-F, et al. Establish a scoring model for high-risk population of gastric cancer and study on the pattern of opportunistic screening. Gastroenterol Res Pract 2020;2020:5609623

15 Wu Y, Su T, Zhou X, et al. Awareness and attitudes regarding Helicobacter pylori infection in Chinese physicians and public population: a national cross-sectional survey. Helicobacter 2020;25:e12705

16 Chen S-Y, Liu T-S, Fan X-M, et al. [Epidemiological study of Helicobacter pylori infection and its risk factors in Shanghai]. Zhonghua Yi Xue Za Zhi 2005;85:802-6.

$17 \mathrm{D}-\mathrm{Y} \mathrm{O}$, Choi KS, Shin H-R. Public awareness of gastric cancer risk factors and disease screening in a high risk region: a populationbased study. Cancer Res Treat2009;41.

18 Shin DW, Cho J, Kim SH, et al. Preferences for the "screen and treat" strategy of Helicobacter pylori to prevent gastric cancer in healthy Korean populations. Helicobacter 2013;18:262-9.

19 Wynne A, Hastings EV, Colquhoun A. Untreated water and Helicobacter pylori: perceptions and behaviors in a northern Canadian community. Int J Circumpol Health 2013;72:704-5.

20 Xia P, Ma M-F, Wang W. Status of Helicobacter pylori infection among migrant workers in Shijiazhuang, China. Asian Pac J Cancer Prev 2012;13:1167-70.

21 Sharma VK, Bailey DM, Raufman JP, et al. A survey of internal medicine residents' knowledge about Helicobacter pylori infection. Am J Gastroenterol 2000;95:1914-9.

22 Liu Q, Zeng X, Wang W, et al. Awareness of risk factors and warning symptoms and attitude towards gastric cancer screening among the general public in China: a cross-sectional study. BMJ Open 2019;9:e029638.

23 Hajian-Tilaki K. Sample size estimation in epidemiologic studies. Caspian J Intern Med 2011;2:289-98.

24 Liu WZ, Xie Y, Lu H, et al. Fifth Chinese national consensus report on the management of Helicobacter pylori infection. Helicobacter 2018;23:e12475.

25 Malek Al, Abdelbagi M, Odeh L, et al. Knowledge, attitudes and practices of adults in the United Arab Emirates regarding Helicobacter pylori induced gastric ulcers and cancers. Asian Pac J Cancer Prev 2021;22:1645-52.

26 Li J, Qiu J, Lv L, et al. Paternal factors and adverse birth outcomes in Lanzhou, China. BMC Pregnancy Childbirth 2021;21:19.

27 Pan Y, Chen R, Li Z, et al. Socioeconomic status and the quality of acute stroke care: the China national stroke Registry. Stroke 2016;47:2836-42.

28 Wang S-S, Lay S, Yu H-N, et al. Dietary guidelines for Chinese residents (2016): comments and comparisons. J Zhejiang Univ Sci B 2016;17:649-56.

29 Teng TZJ, Sudharsan M, Yau JWK, et al. Helicobacter pylori knowledge and perception among multi-ethnic Asians. Helicobacter 2021;26:e12794.

30 Li W-Q, Zhang J-Y, Ma J-L, et al. Effects of Helicobacter pylori treatment and vitamin and garlic supplementation on gastric cancer incidence and mortality: follow-up of a randomized intervention trial. BMJ 2019;366:I5016.

31 Melese A, Genet C, Zeleke B, et al. Helicobacter pylori infections in Ethiopia; prevalence and associated factors: a systematic review and meta-analysis. BMC Gastroenterol 2019;19:8.

32 Qin L, Xu H. A cross-sectional study of the effect of health literacy on diabetes prevention and control among elderly individuals with prediabetes in rural China. BMJ Open 2016;6:e011077.

33 Arber S, Ginn J, et al. Gender differences in informal caring. Health Soc Care Community 2007;3:19-31.

34 Huang R-L, Liu Q, Wang Y-X, et al. Awareness, attitude and barriers of colorectal cancer screening among high-risk populations in China: a cross-sectional study. BMJ Open 2021;11:e045168.

35 Inoue M. Changing epidemiology of Helicobacter pylori in Japan. Gastric Cancer 2017;20:3-7.

36 Emmons KM, Colditz GA. Realizing the Potential of Cancer Prevention - The Role of Implementation Science. N Engl J Med 2017;376:986-90.

37 Chief C, Sanderson PR, Willeto AAA, et al. "Nobody Is Talking About It": Diné (Navajo) Communities Speak About Stomach Cancer and Helicobacter pylori Infections. J Cancer Educ 2020. doi:10.1007/s13187-020-01831-0. [Epub ahead of print: 22 Jul 2020]

38 Deng S-X, Gao J, An W, et al. Colorectal cancer screening behavior and willingness: an outpatient survey in China. World J Gastroentero 2011;17:3133-9.

39 Fisher WA, Fisher JD, Harman J. The Information-MotivationBehavioral skills model: a general social psychological approach to understanding and promoting health behavior. Blackwell Publishing Ltd, 2003.

40 Driscoll LJ, Brown HE, Harris RB, et al. Population Knowledge, Attitude, and Practice Regarding Helicobacter pylori Transmission and Outcomes: A Literature Review. Front Public Health 2017;5:144.

41 Jung MY, Holt CL, Ng D, et al. The Chinese and Korean American immigrant experience: a mixed-methods examination of 
facilitators and barriers of colorectal cancer screening. Ethn Health 2018;23:847-66.

$42 \mathrm{Sin}$ M-K, Kim I-H. Facilitators of and barriers to gastric cancer screening among Korean Americans. Cancer Nurs 2017;40:E59-65.

43 Nie Y, Wu K, Yu J, et al. A global burden of gastric cancer: the major impact of China. Expert Rev Gastroenterol Hepatol 2017;11:651-61.

44 Guan X, Ni B, Zhang J. Association between physicians' workload and prescribing quality in one tertiary hospital in China. J Patient Saf 2020.

45 White A, Thompson TD, White MC, et al. Cancer Screening Test Use - United States, 2015. MMWR Morb Mortal Wkly Rep 2017;66:201-6.

46 Sin M-K, Ha A, Taylor V. Sociocultural barriers to lung cancer screening among Korean immigrant men. J Community Health 2016;41:790-7.

47 Leja M, Grinberga-Derica I, Bilgilier C, et al. Review: epidemiology of Helicobacter pylori infection. Helicobacter 2019;24 Suppl 1:e12635.

48 Razuka-Ebela D, Polaka I, Parshutin S, et al. Sociodemographic, lifestyle and medical factors associated with Helicobacter pylori infection. J Gastrointestin Liver Dis 2020;29:319-27.

49 Wang T, Cai H, Sasazuki S, et al. Fruit and vegetable consumption, Helicobacter pylori antibodies, and gastric cancer risk: a pooled analysis of prospective studies in China, Japan, and Korea. Int $J$ Cancer 2017;140:591-9.
50 Gebara ECE, Faria CM, Pannuti C, et al. Persistence of Helicobacter pylori in the oral cavity after systemic eradication therapy. J Clin Periodontol 2006;33:329-33.

51 Xu Y-E, Li S-X, Gao X, et al. [Risk factors of oral Helicobacter pylori infection among children in two kindergartens in Suzhou and the effects of oral cleaning on reducing oral Helicobacter pylori infection]. Hua Xi Kou Qiang Yi Xue Za Zhi 2019;37:70-5.

52 Monno R, De Laurentiis V, Trerotoli P, et al. Helicobacter pylor infection: association with dietary habits and socioeconomic conditions. Clin Res Hepatol Gastroenterol 2019;43:603-7.

53 Tang MYL, Chung PHY, Chan HY, et al. Recent trends in the prevalence of Helicobacter pylori in symptomatic children: a 12-year retrospective study in a tertiary centre. J Pediatr Surg 2019;54:255-7.

54 Asaka M, Kato M, Takahashi S-ichi, et al. Guidelines for the management of Helicobacter pylori infection in Japan: 2009 revised edition. Helicobacter 2010;15:1-20.

55 Asaka M, Mabe K, Matsushima R, et al. Helicobacter pylori eradication to eliminate gastric cancer: the Japanese strategy. Gastroenterol Clin North Am 2015;44:639-48.

56 Hiroi S, Sugano K, Tanaka S, et al. Impact of health insurance coverage for Helicobacter pylori gastritis on the trends in eradication therapy in Japan: retrospective observational study and simulation study based on real-world data. BMJ Open 2017;7:e015855.

57 Sugano K. Strategies for prevention of gastric cancer: progress from mass eradication trials. Dig Dis 2016;34:500-4. 